\title{
Article \\ The Prevalence and Correlates of Probable Major Depressive Disorder and Probable Generalized Anxiety Disorder during the COVID-19 Pandemic. Results of a Nationally Representative Survey in Germany
}

\author{
André Hajek * (D) and Hans-Helmut König (D) \\ Hamburg Center for Health Economics, Department of Health Economics and Health Services Research, \\ University Medical Center Hamburg-Eppendorf, 20246 Hamburg, Germany; h.koenig@uke.de \\ * Correspondence: a.hajek@uke.de; Tel.: +49-40-7410-52877; Fax: +49-40-7410-40261
}

\section{check for}

updates

Citation: Hajek, A.; König, H.-H. The Prevalence and Correlates of Probable Major Depressive Disorder and Probable Generalized Anxiety Disorder during the COVID-19 Pandemic. Results of a Nationally Representative Survey in Germany. Int. J. Environ. Res. Public Health 2021, 18, 12302. https://doi.org/10.3390/ ijerph182312302

Academic Editor: Paul B. Tchounwou

Received: 6 October 2021

Accepted: 18 November 2021

Published: 23 November 2021

Publisher's Note: MDPI stays neutral with regard to jurisdictional claims in published maps and institutional affiliations.

Copyright: (c) 2021 by the authors. Licensee MDPI, Basel, Switzerland. This article is an open access article distributed under the terms and conditions of the Creative Commons Attribution (CC BY) license (https:// creativecommons.org/licenses/by/ $4.0 /)$.
Abstract: The aim was to clarify the prevalence and correlates of probable major depressive disorder and probable generalized anxiety disorder in the general adult population during the COVID-19 pandemic. Data were derived from a nationally representative survey (August and September 2021). In total, $n=3075$ individuals took part. To quantify probable generalized anxiety disorder, the established Generalized Anxiety Disorder-7 (GAD-7; cutoff of 10) was used. Moreover, the Patient Health Questionnaire-9 (PHQ-9; cutoff of 10) was used to quantify probable major depressive disorder. The prevalence of probable major depressive disorder was $20.0 \%$ and the prevalence of probable generalized anxiety disorder was $13.4 \%$. Particularly high prevalence rates were observed for younger individuals, individuals with migration background and individuals with at least one chronic disease. The likelihood of probable major depressive disorder was positively associated with younger age, being unmarried, having a migration background, smoking, daily alcohol intake, the presence of chronic diseases and lower self-rated health. Similarly, the likelihood of probable generalized anxiety disorder was positively associated with younger age, being unmarried, smoking, the presence of chronic diseases and lower self-rated health. In conclusion, the magnitude of probable major depressive disorder and probable generalized anxiety disorder in Germany in late summer of 2021 was highlighted. Identifying the correlates of them may help to tackle individuals at higher risk.

Keywords: prevalence; depression; anxiety; Patient Health Questionnaire (PHQ); generalized anxiety disorder; mental disorders; SARS-CoV-2; COVID-19

\section{Introduction}

High prevalence rates of depression and anxiety have repeatedly been shown in the past [1,2]. In times of the current pandemic, individuals are confronted with several challenges including social distancing [3] and economic uncertainties. According to a metaanalysis (including general populations globally during the pandemic), the prevalence of anxiety and depression was 32\% (95\% CI: 28-37) and 34\% (95\% CI: 28-41), respectively [4]. Globally, it should be emphasized that most of the studies used convenience samples and only some studies using nationally representative samples (from a specific country, e.g., United Kingdom, Austria, United States, Australia, Scotland or Republic of Ireland) during the pandemic (e.g., [5-15]).

Furthermore, globally, most of the existing studies focused on the pandemic in the year 2020, whereas only a few nationally representative studies exist identifying the prevalence and correlates of probable major depressive disorder and probable generalized anxiety disorder in the year 2021.

This is of importance because vaccinations against COVID-19 have been available since the end of 2020 (in various countries including Germany). These vaccinations are recom- 
mended by, for example, the Food and Drug Administration, the European Medicines Agency and by the Standing Committee on Vaccination at the Robert Koch Institute (Germany).

Consequently, our objective was to identify the prevalence and correlates of probable major depressive disorder and probable generalized anxiety disorder in the general adult population during the COVID-19 pandemic (late summer of 2021). Knowledge regarding the correlates of these disorders may assist in characterizing at-risk individuals. This in turn may be beneficial to reduce the likely rise in these mental disorders [16].

\section{Materials and Methods}

\subsection{Sample}

For our current study, data were used from a nationally representative online survey covering individuals aged 18 to 70 years and living in Germany $(n=3075)$. Thus, the only inclusion criteria were the following: aged 18 to 70 years and residing in Germany. This also means that individuals aged 17 and younger and individuals aged 71 years and over were excluded. Moreover, individuals not residing in Germany were excluded. Other exclusion criteria did not exist. However, the questionnaire was only available in the German language. Thus, it is most likely that individuals who could not read German did not participate.

The survey took place from 24 August to 3 September 2021. The participants were recruited by a well-known market research company, which owns an online access panel. For this online sample, multiple recruitment sources were used (e.g., opinion platforms, search engine marketing or cooperation agreements).

Respondents were drawn from this online sample in a way that corresponded to the distribution of age group, gender and federal state in the general German population [17] (based on these sociodemographic data, a random sample from the population of the online access panel was drawn). The quotas were from Best for Planning 2020. About 14,000 individuals were invited to participate. There was a maximum of two reminders after the initial invitation mail (thus, three mails in total). The interval between two reminders was at least two days. To avoid duplicates (i.e., multiple registrations from the same individual), digital fingerprint solutions were used.

Participants provided informed consent. The study was approved by the Local Psychological Ethics Committee of the Center for Psychosocial Medicine of the University Medical Center Hamburg-Eppendorf (number: LPEK-0356).

\subsection{Outcome}

Patient Health Questionnaire-9 (PHQ-9) was used to quantify probable major depressive disorder. It is a widely used (e.g., [18]) and valid tool consisting of nine items [19]. As an example, individuals were asked, how often they feel bothered by "little interest or pleasure in doing things" in the past two weeks (not at all; several days; more than half of the days; nearly every day). A sum score was computed ranging from 0 to 27 , with higher scores indicating more depressive symptoms. Based on a PHQ-9 score of $\geq 10$, the sensitivity was 0.88 and the specificity was 0.88 for major depressive disorder [19]. In our study, Cronbach's alpha was 0.91. In line with previous studies, a cutoff of $\geq 10$ was used in our study [20].

Generalized Anxiety Disorder-7 (GAD-7; cutoff of 10) was used to assess probable generalized anxiety disorder [21]. It consists of seven items. A sum score was calculated (from 0 to 21), with higher scores indicating more anxiety symptoms. The sensitivity was 0.89 and the specificity was 0.82 (when GAD-7 score $\geq 10$ ). In our study, Cronbach's alpha was 0.92. Based on the existing recommendations [21], the cutoff of $\geq 10$ was used in our study.

\subsection{Independent Variables}

As correlates, we included the following in regression analysis (all were self-reported): gender, age, marital status (married, living together with spouse; married, not living 
together with spouse; widowed; divorced; single), presence of children in the same household (no or yes), migration background (no or yes), highest educational degree (upper secondary school; qualification for applied upper secondary school; polytechnic secondary school; intermediate secondary school; lower secondary school; currently in school training/education; without school-leaving qualification) and employment status (full-time employed; retired; other).

Additionally, we included smoking behavior (yes, daily; yes, sometimes; no, not anymore; never smoker), alcohol consumption (daily; several times per week; once a week; 1-3 times per month; less often; never), and sports activities (no sports activity; less than one hour a week; regularly, 1-2 h a week; regularly, 2-4 h a week; regularly, more than $4 \mathrm{~h}$ a week). Additionally, vaccinated against COVID-19 (no or yes), chronic diseases (absence of chronic diseases; presence of one or more chronic diseases; exact wording: "Do you have at least one chronic condition?"; no or yes) and self-rated health (exact wording: "How would you rate your current health?"; 1 = very bad; 2 = poor; 3 = average; 4 = good; $5=$ very good) were included as covariates.

\subsection{Statistical Analysis}

First, prevalence rates are displayed (also stratified by several sociodemographic factors such as age group and health-related factors). Thereafter, multiple logistic regressions were conducted (first regression: with probable major depressive disorder as the outcome measure; second regression: with probable generalized anxiety disorder as the outcome measure). It should be noted that we dichotomized the marital status (0: married, not living together with spouse; widowed; divorced; single; 1 : married, living together with spouse). The level of significance was set at $p<0.05$. Stata 16.1 (Stata Corp., College Station, TX, USA) was used for performing statistical analyses.

\section{Results}

\subsection{Key Sample Characteristics and Prevalence Rates}

In our sample, the average age equaled 44.5 years (SD: 14.8 years). Furthermore, 51.1\% of the participants were female. A comparison of the target cohort and our sample is given in Supplementary Table S1. Prevalence rates for probable major depressive disorder and probable generalized anxiety disorder (also stratified by several sociodemographic and health-related factors) are displayed in Table 1.

Table 1. Prevalence rate for major depressive disorder and probable generalized anxiety disorder among several groups.

\begin{tabular}{cccc}
\hline & $n$ & $\begin{array}{c}\text { Presence of Probable Major } \\
\text { Depressive Disorder }\end{array}$ & $\begin{array}{c}\text { Presence of Probable } \\
\text { Generalized Anxiety Disorder }\end{array}$ \\
\hline Total sample & 3075 & $614(20.0 \%)$ & $412(13.4 \%)$ \\
\hline Gender & & & $249(16.6 \%)$ \\
\hline Male & 1502 & $363(23.1 \%)$ & $247(15.7 \%)$ \\
\hline Female & 1570 & $2(66.7 \%)$ & $1(33.3 \%)$ \\
\hline Diverse & 3 & $200(31.8 \%)$ & $145(23.1 \%)$ \\
\hline Age group & & $126(21.1 \%)$ & $87(14.6 \%)$ \\
\hline 18 to 29 years & 628 & $105(17.6 \%)$ & $72(12.1 \%)$ \\
\hline 40 to 39 years & 597 years & $113(17.1 \%)$ & $72(10.9 \%)$ \\
\hline 50 to 59 years & 597 & $70(11.8 \%)$ & $36(6.1 \%)$ \\
\hline
\end{tabular}

Children in own household 
Table 1. Cont

\begin{tabular}{|c|c|c|c|}
\hline & $n$ & $\begin{array}{l}\text { Presence of Probable Major } \\
\text { Depressive Disorder }\end{array}$ & $\begin{array}{c}\text { Presence of Probable } \\
\text { Generalized Anxiety Disorder }\end{array}$ \\
\hline No & 2206 & $461(20.9 \%)$ & $311(14.1 \%)$ \\
\hline Yes & 869 & $153(17.6 \%)$ & $101(11.6 \%)$ \\
\hline \multicolumn{4}{|l|}{ Marital status } \\
\hline $\begin{array}{l}\text { Single/divorced/widowed/married, } \\
\text { not living together with spouse }\end{array}$ & 1313 & $340(25.9 \%)$ & $230(17.5 \%)$ \\
\hline Married, living together with spouse & 1762 & $274(15.6 \%)$ & $182(10.3 \%)$ \\
\hline \multicolumn{4}{|l|}{ Education } \\
\hline Upper secondary school & 1326 & $251(18.9 \%)$ & $183(13.8 \%)$ \\
\hline $\begin{array}{l}\text { Qualification for applied upper } \\
\text { secondary school }\end{array}$ & 328 & $66(20.1 \%)$ & $38(11.6 \%)$ \\
\hline Polytechnic secondary school & 168 & $23(13.7 \%)$ & $12(7.1 \%)$ \\
\hline Intermediate secondary school & 888 & $192(21.6 \%)$ & $119(13.4 \%)$ \\
\hline Lower secondary school & 347 & $75(21.6 \%)$ & $55(15.9 \%)$ \\
\hline Currently in school training/education & 9 & $2(22.2 \%)$ & $1(11.1 \%)$ \\
\hline Without school-leaving qualification & 9 & $5(55.6 \%)$ & $4(44.4 \%)$ \\
\hline \multicolumn{4}{|l|}{ Migration background } \\
\hline No & 2724 & $508(18.6 \%)$ & $344(12.6 \%)$ \\
\hline Yes & 351 & $106(30.2 \%)$ & $68(19.4 \%)$ \\
\hline \multicolumn{4}{|l|}{ Employment status } \\
\hline Full-time employed & 1458 & $237(16.3 \%)$ & $166(11.4 \%)$ \\
\hline Retired & 499 & $86(17.2 \%)$ & $48(9.6 \%)$ \\
\hline Other & 1118 & $291(26.0 \%)$ & $198(17.7 \%)$ \\
\hline \multicolumn{4}{|l|}{ Vaccinated against COVID-19 } \\
\hline No & 593 & $130(21.9 \%)$ & $98(16.5 \%)$ \\
\hline Yes & 2482 & $484(19.5 \%)$ & $314(12.7 \%)$ \\
\hline \multicolumn{4}{|l|}{ Chronic diseases } \\
\hline Absence of at least one chronic disease & 1765 & $254(14.4 \%)$ & $183(10.4 \%)$ \\
\hline Presence of at least one chronic disease & 1310 & $360(27.5 \%)$ & $229(17.5 \%)$ \\
\hline
\end{tabular}

The prevalence of probable major depressive disorder was $20.0 \%$ and the prevalence of probable generalized anxiety disorder was $13.4 \%$. Particularly high prevalence rates were identified among younger individuals aged 18 to 29 years (probable major depressive disorder: $31.8 \%$; probable generalized anxiety disorder: $23.1 \%$ ), among individuals with migration background (probable major depressive disorder: $30.2 \%$; probable generalized anxiety disorder: $19.4 \%$ ) and among individuals with at least one chronic disease (probable major depressive disorder: $27.5 \%$; probable generalized anxiety disorder: $17.5 \%$ ).

\subsection{Regression Analysis}

The findings of multiple logistic regressions are shown in Table 2.

The likelihood of probable major depressive disorder was positively associated with younger age (OR: 0.94, 95\% CI: 0.93-0.95), being unmarried (OR: 0.73, 95\% CI: 0.58-0.90), having a migration background (OR: 1.60, 95\% CI: 1.19-1.60), smoking (e.g., "Yes, sometimes" compared to "never smoker", OR: 1.85, 95\% CI: 1.28-2.66), daily alcohol intake 
(compared to "never", OR: 1.63, 95\% CI: 1.01-2.64), the presence of chronic diseases (OR: 1.78, 95\% CI: 1.40-2.25) and lower self-rated health (OR: 0.29, 95\% CI: 0.25-0.34).

Table 2. Correlates of probable major depressive disorder and probable generalized anxiety disorder. Results of multiple logistic regressions.

\begin{tabular}{|c|c|c|c|}
\hline \multicolumn{2}{|c|}{ Independent Variables } & \multirow{2}{*}{$\begin{array}{c}\begin{array}{c}\text { Probable Major } \\
\text { Depressive Disorder }\end{array} \\
1.18 \\
(0.94-1.49)\end{array}$} & \multirow{2}{*}{$\begin{array}{c}\text { Probable Generalized } \\
\text { Anxiety Disorder } \\
1.24 \\
(0.95-1.61)\end{array}$} \\
\hline Sex: & - Women (Ref.: men) & & \\
\hline & - Diverse & 2.76 & 0.71 \\
\hline & & $(0.19-41.01)$ & $(0.04-14.50)$ \\
\hline \multirow[t]{2}{*}{ Age (in years) } & & $0.94^{* * *}$ & $0.94^{* * *}$ \\
\hline & & $(0.93-0.95)$ & $(0.93-0.95)$ \\
\hline \multirow[t]{2}{*}{ Children in own household: } & - Yes (Reference: no) & 0.91 & 0.89 \\
\hline & & $(0.71-1.16)$ & $(0.67-1.18)$ \\
\hline \multirow[t]{2}{*}{ Marital status: } & $\begin{array}{l}\text { - Married, living together with spouse (Ref.: } \\
\text { single/divorced/widowed/married, not } \\
\text { living together with spouse) }\end{array}$ & $0.73^{* *}$ & $0.77 *$ \\
\hline & & $(0.58-0.90)$ & $(0.60-0.99)$ \\
\hline \multirow[t]{11}{*}{ Highest educational degree: } & $\begin{array}{l}\text { - Qualification for applied upper secondary } \\
\text { school (Ref.: upper secondary school) }\end{array}$ & 1.00 & 0.72 \\
\hline & & $(0.71-1.42)$ & $(0.47-1.09)$ \\
\hline & - Polytechnic secondary school & $\begin{array}{c}0.74 \\
(0.43-1.26)\end{array}$ & $\begin{array}{c}0.53+ \\
(0.27-1.06)\end{array}$ \\
\hline & - Intermediate secondary school & 1.09 & 0.88 \\
\hline & & $(0.84-1.41)$ & $(0.65-1.18)$ \\
\hline & - Lower secondary school & 1.14 & 1.26 \\
\hline & & $(0.79-1.64)$ & $(0.84-1.88)$ \\
\hline & - Currently in school training/education & 0.85 & 0.58 \\
\hline & & $(0.14-4.99)$ & $(0.06-5.16)$ \\
\hline & - Without school-leaving qualification & 1.56 & 1.62 \\
\hline & & $(0.35-6.84)$ & $(0.37-7.10)$ \\
\hline \multirow[t]{2}{*}{ Migration: } & $\begin{array}{l}\text { - Migration background (Ref.: no migration } \\
\text { background) }\end{array}$ & $1.60^{* *}$ & 1.26 \\
\hline & & $(1.19-2.15)$ & $(0.90-1.75)$ \\
\hline \multirow[t]{4}{*}{ Employment status: } & - Retired (Ref.: full-time employed) & 0.96 & 0.76 \\
\hline & & $(0.67-1.38)$ & $(0.49-1.17)$ \\
\hline & - Other & 1.05 & 0.96 \\
\hline & & $(0.83-1.33)$ & $(0.74-1.25)$ \\
\hline \multirow[t]{6}{*}{ Smoking: } & - Yes, daily (Ref: never smoker) & $1.36^{*}$ & 1.25 \\
\hline & & $(1.03-1.80)$ & $(0.91-1.73)$ \\
\hline & - Yes, sometimes & $1.85^{* * *}$ & $2.16^{* * *}$ \\
\hline & & $(1.28-2.66)$ & $(1.45-3.22)$ \\
\hline & - No, not anymore & 1.24 & 1.13 \\
\hline & & $(0.94-1.63)$ & $(0.82-1.55)$ \\
\hline \multirow[t]{8}{*}{ Sports activities: } & $\begin{array}{l}\text { - Less than one hour a week (Ref.: no } \\
\text { sports activity) }\end{array}$ & 1.18 & 1.04 \\
\hline & & $(0.89-1.57)$ & $(0.75-1.46)$ \\
\hline & - Regularly, 1-2 h a week & 1.20 & 1.18 \\
\hline & & $(0.89-1.60)$ & $(0.84-1.65)$ \\
\hline & - Regularly, 2-4 h a week & 0.96 & 1.25 \\
\hline & & $(0.68-1.37)$ & $(0.84-1.84)$ \\
\hline & - Regularly, more than $4 \mathrm{~h}$ a week & 0.90 & 1.20 \\
\hline & & $(0.61-1.33)$ & $(0.78-1.84)$ \\
\hline \multirow[t]{6}{*}{ Alcohol intake: } & - Daily (Ref.: never) & $1.63 *$ & 1.45 \\
\hline & & $(1.01-2.64)$ & $(0.83-2.53)$ \\
\hline & - Several times a week & 1.30 & 1.33 \\
\hline & & $(0.92-1.85)$ & $(0.90-1.97)$ \\
\hline & - Once a week & 1.18 & 1.25 \\
\hline & & $(0.83-1.69)$ & $(0.84-1.87)$ \\
\hline
\end{tabular}


Table 2. Cont

\begin{tabular}{|c|c|c|c|}
\hline \multicolumn{2}{|c|}{ Independent Variables } & \multirow{2}{*}{$\begin{array}{c}\begin{array}{c}\text { Probable Major } \\
\text { Depressive Disorder }\end{array} \\
0.95 \\
(0.68-1.33)\end{array}$} & \multirow{2}{*}{$\begin{array}{c}\text { Probable Generalized } \\
\text { Anxiety Disorder } \\
0.82 \\
(0.55-1.21)\end{array}$} \\
\hline & $\begin{array}{l}\text { - 1-3 times a month } \\
\text { - Less often }\end{array}$ & & \\
\hline Vaccinated against COVID-19: & - Yes (Ref.: no) & $\begin{array}{c}1.12 \\
(0.86-1.45)\end{array}$ & $\begin{array}{c}0.91 \\
(0.68-1.22)\end{array}$ \\
\hline Chronic diseases: & $\begin{array}{l}\text { - Presence of at least one chronic disease } \\
\text { (absence of chronic diseases) }\end{array}$ & $\begin{array}{c}1.78^{* * *} \\
(1.40-2.25)\end{array}$ & $\begin{array}{c}1.44^{* *} \\
(1.09-1.88)\end{array}$ \\
\hline $\begin{array}{l}\text { Self-rated health }(1=\text { very bad } \\
\text { to } 5=\text { very good })\end{array}$ & & $0.29 * * *$ & $0.29 * * *$ \\
\hline Constant & & $\begin{array}{c}(0.25-0.34) \\
110.89 * * * \\
(49.52-248.31)\end{array}$ & $\begin{array}{c}(0.25-0.34) \\
89.08^{* * *} \\
(36.32-218.52)\end{array}$ \\
\hline $\begin{array}{l}\text { Pseudo } \mathrm{R}^{2} \\
\text { Observations }\end{array}$ & & $\begin{array}{r}0.22 \\
3075\end{array}$ & $\begin{array}{l}0.20 \\
3075\end{array}$ \\
\hline
\end{tabular}

Odds ratios are displayed; $95 \%$ confidence intervals in parentheses; ${ }^{* * *} p<0.001,{ }^{* *} p<0.01,{ }^{*} p<0.05,+p<0.10$; continuous variables included in regression analysis were as follows: age and self-rated health. All other independent variables were nominal or categorical.

The likelihood of probable generalized anxiety disorder was positively associated with younger age (OR: 0.94, 95\% CI: 0.93-0.95), being unmarried (OR: 0.77, 95\% CI: 0.60-0.99), smoking ("Yes, sometimes" compared to "never smoker", OR: 2.16, 95\% CI: 1.45-3.22), the presence of chronic diseases (OR: 1.44, 95\% CI: 1.09-1.88) and lower self-rated health (OR: 0.29 , 95\% CI: $0.25-0.34$ ).

\section{Discussion}

\subsection{Main Findings}

Using data from the general adult population, our goal was to clarify the prevalence and correlates of probable major depressive disorder and probable generalized anxiety disorder in late summer of 2021. While the prevalence of probable major depressive disorder was $20.0 \%$, the prevalence of probable generalized anxiety disorder was $13.4 \%$. Particularly high prevalence rates were identified among younger individuals aged 18 to 29 years, among individuals with migration background and among individuals with at least one chronic disease. Some groups (gender: diverse; without school-leaving qualification) also reported very high prevalence rates. However, sample sizes were very small for these groups and these findings should, therefore, be treated with great caution.

Similar correlates were identified for both probable major depressive disorder and probable generalized anxiety disorder (e.g., younger age, lifestyle factors and healthrelated factors).

\subsection{Previous Research and Possible Explanations}

Our study showed that probable major depressive disorder and probable generalized anxiety disorder are frequent in the general adult population in Germany. These prevalence rates were higher compared to almost ten years ago (based on the PHQ-4 cutoff values: $10.4 \%$ of the individuals had probable depression and $9.8 \%$ of the individuals had probable anxiety) [22]. However, compared to April 2021, prevalence rates were slightly lower for probable major depressive disorder $(23.7 \%)$, whereas they were markedly lower for probable generalized anxiety disorder in Germany (22.3\%) [23]. This may be explained by differences in the tools used (GAD-2 versus GAD-7). Moreover, individuals may have adapted to the conditions of the pandemic and may have overcome times of economic challenges, health concerns and loneliness.

The highest prevalence rates were identified among young adults, individuals with migration background and individuals with one or more chronic diseases. In particular, 
young adults may be confronted with challenges such as financial hardships or concerns about the future. Similar findings were made by Ranta et al. in Finland [24]. Such factors may explain their high prevalence rates. Individuals with chronic diseases may fear a potential severe course of an infection with the corona virus. Therefore, they may have comparably high prevalence rates. Moreover, individuals with a migration background may have high prevalence rates since they may be concerned about friends and relatives who may live abroad. They may fear that they cannot visit these friends and relatives in case of emergency due to potential travel restrictions. Such concerns were also described by a recent qualitative study examining different migrant groups living in Finland during the pandemic [25]. Additionally, fear due to insufficient knowledge about the coronavirus (resulting from language barriers) may also explain the comparably high prevalence rates. Apart from that, the correlates of probable major depressive disorder and probable generalized anxiety disorder (e.g., sociodemographic factors, lifestyle-related factors and health-related factors) during late summer 2021 are well in line with previous studies (e.g., [26]). For example, previous research also demonstrated associations between cigarette smoking [27] or marital status [28] and our outcomes.

\subsection{Strengths and Limitations}

Some strengths and limitations are worth acknowledging. Data came from a representative sample (collected in late summer of 2021). Both outcomes are valid, and there are well-established tools to quantify probable major depressive disorder and probable generalized anxiety disorder. However, upcoming studies based on clinical interviews are preferable to confirm our findings. Moreover, future longitudinal studies are required. It should be noted that our online survey was only available in the German language. Moreover, potential differences between non-respondents and respondents could not be calculated.

\section{Conclusions and Future Research}

Our current study extends our knowledge regarding the level of probable major depressive disorder and probable generalized anxiety disorder in the general adult population in Germany. The magnitude of probable major depressive disorder and probable generalized anxiety disorder in Germany in late summer 2021 was highlighted. Identifying the correlates of these disorders may help to tackle individuals at higher risk. Ultimately, this knowledge may assist in reducing the projected rise in mental disorders [16]. Future research is required in this area, for example, based on longitudinal data. Moreover, future research is required to clarify what consequences this expected increase in mental disorders has for different outcomes (e.g., morbidity and mortality).

Supplementary Materials: The following are available online at https:/ /www.mdpi.com/article/10 .3390/ijerph182312302/s1, Table S1: Comparison of the target quote and our sample.

Author Contributions: A.H.: conceptualization; data curation; methodology; project administration, visualization; roles/writing-original draft, writing—review and editing, formal analysis. H.-H.K.: conceptualization; resources; writing — review and editing; supervision; visualization. All authors have read and agreed to the published version of the manuscript.

Funding: This research received no external funding.

Institutional Review Board Statement: The study was approved by the Local Psychological Ethics Committee of the Center for Psychosocial Medicine of the University Medical Center HamburgEppendorf (number: LPEK-0356).

Informed Consent Statement: Participants provided informed consent.

Data Availability Statement: The datasets used and analyzed during the current study are available from the corresponding author on reasonable request for all interested researchers.

Conflicts of Interest: The authors declare no conflict of interest. 


\section{References}

1. Kessler, R.C.; Berglund, P.; Demler, O.; Jin, R.; Koretz, D.; Merikangas, K.R.; Rush, A.J.; Walters, E.E.; Wang, P.S. The epidemiology of major depressive disorder: Results from the National Comorbidity Survey Replication (NCS-R). JAMA 2003, 289, 3095-3105. [CrossRef]

2. Somers, J.M.; Goldner, E.M.; Waraich, P.; Hsu, L. Prevalence and incidence studies of anxiety disorders: A systematic review of the literature. Can. J. Psychiatry 2006, 51, 100-113. [CrossRef]

3. Stolz, E.; Mayerl, H.; Freidl, W. The impact of COVID-19 restriction measures on loneliness among older adults in Austria. Eur. J. Public Health 2021, 31, 44-49. [CrossRef]

4. Salari, N.; Hosseinian-Far, A.; Jalali, R.; Vaisi-Raygani, A.; Rasoulpoor, S.; Mohammadi, M.; Rasoulpoor, S.; Khaledi-Paveh, B. Prevalence of stress, anxiety, depression among the general population during the COVID-19 pandemic: A systematic review and meta-analysis. Glob. Health 2020, 16, 57. [CrossRef] [PubMed]

5. Budimir, S.; Pieh, C.; Dale, R.; Probst, T. Severe Mental Health Symptoms during COVID-19: A Comparison of the United Kingdom and Austria. Healthcare 2021, 9, 191. [CrossRef] [PubMed]

6. Czeisler, M.É.; Howard, M.E.; Robbins, R.; Barger, L.K.; Facer-Childs, E.R.; Rajaratnam, S.M.; Czeisler, C.A. Early public adherence with and support for stay-at-home COVID-19 mitigation strategies despite adverse life impact: A transnational cross-sectional survey study in the United States and Australia. BMC Public Health 2021, 21, 503. [CrossRef]

7. Daly, M.; Robinson, E. Anxiety reported by US adults in 2019 and during the 2020 COVID-19 pandemic: Population-based evidence from two nationally representative samples. J. Affect. Disord. 2021, 286, 296-300. [CrossRef]

8. Hou, W.K.; Lee, T.M.-C.; Liang, L.; Li, T.W.; Liu, H.; Ettman, C.K.; Galea, S. Civil unrest, COVID-19 stressors, anxiety, and depression in the acute phase of the pandemic: A population-based study in Hong Kong. Soc. Psychiatry Psychiatr. Epidemiol. 2021, 56, 1499-1508. [CrossRef]

9. Hou, W.K.; Lee, T.M.-c.; Liang, L.; Li, T.W.; Liu, H.; Tong, H.; Ben-Ezra, M.; Goodwin, R. Psychiatric symptoms and behavioral adjustment during the COVID-19 pandemic: Evidence from two population-representative cohorts. Transl. Psychiatry 2021, 11, 174. [CrossRef]

10. Hubbard, G.; den Daas, C.; Johnston, M.; Dixon, D. Sociodemographic and psychological risk factors for anxiety and depression: Findings from the COVID-19 health and adherence research in Scotland on mental health (CHARIS-MH) cross-sectional survey. Int. J. Behav. Med. 2021, 28, 788-800. [CrossRef] [PubMed]

11. Hyland, P.; Shevlin, M.; McBride, O.; Murphy, J.; Karatzias, T.; Bentall, R.P.; Martinez, A.; Vallières, F. Anxiety and depression in the Republic of Ireland during the COVID-19 pandemic. Acta Psychiatr. Scand. 2020, 142, 249-256. [CrossRef]

12. Hyland, P.; Shevlin, M.; Murphy, J.; McBride, O.; Fox, R.; Bondjers, K.; Karatzias, T.; Bentall, R.P.; Martinez, A.; Vallières, F. A longitudinal assessment of depression and anxiety in the Republic of Ireland before and during the COVID-19 pandemic Psychiatry Res. 2021, 300, 113905. [CrossRef]

13. Röhr, S.; Reininghaus, U.; Riedel-Heller, S.G. Mental wellbeing in the German old age population largely unaltered during COVID-19 lockdown: Results of a representative survey. BMC Geriatr. 2020, 20, 489. [CrossRef] [PubMed]

14. Twenge, J.M.; Joiner, T.E. US Census Bureau-assessed prevalence of anxiety and depressive symptoms in 2019 and during the 2020 COVID-19 pandemic. Depress. Anxiety 2020, 37, 954-956. [CrossRef]

15. Winkler, P.; Formanek, T.; Mlada, K.; Kagstrom, A.; Mohrova, Z.; Mohr, P.; Csemy, L. Increase in prevalence of current mental disorders in the context of COVID-19: Analysis of repeated nationwide cross-sectional surveys. Epidemiol. Psychiatr. Sci. 2020, 29, e173. [CrossRef] [PubMed]

16. Riedel-Heller, S.; Richter, D. COVID-19 pandemic and mental health of the general public: Is there a tsunami of mental disorders? Psychiatr. Prax. 2020, 47, 452-456.

17. Münnich, R.; Gabler, S. 2012: Stichprobenoptimierung und Schätzung in Zensus 2011; Statistisches Bundesamt: Wiesbaden, Germany, 2012; Volume 21.

18. Lin, L.-Y.; Wang, J.; Ou-Yang, X.-Y.; Miao, Q.; Chen, R.; Liang, F.-X.; Zhang, Y.-P.; Tang, Q.; Wang, T. The immediate impact of the 2019 novel coronavirus (COVID-19) outbreak on subjective sleep status. Sleep Med. 2021, 77, 348-354. [CrossRef] [PubMed]

19. Kroenke, K.; Spitzer, R.L.; Williams, J.B. The PHQ-9: Validity of a brief depression severity measure. J. Gen. Intern. Med. 2001, 16, 606-613. [CrossRef]

20. Manea, L.; Gilbody, S.; McMillan, D. Optimal cut-off score for diagnosing depression with the Patient Health Questionnaire (PHQ-9): A meta-analysis. CMAJ 2012, 184, E191-E196. [CrossRef]

21. Spitzer, R.L.; Kroenke, K.; Williams, J.B.; Löwe, B. A brief measure for assessing generalized anxiety disorder: The GAD-7. Arch Intern. Med. 2006, 166, 1092-1097. [CrossRef]

22. Hajek, A.; König, H.-H. Prevalence and Correlates of Individuals Screening Positive for Depression and Anxiety on the PHQ-4 in the German General Population: Findings from the Nationally Representative German Socio-Economic Panel (GSOEP). Int. J. Environ. Res. Public Health 2020, 17, 7865. [CrossRef] [PubMed]

23. Hajek, A.; Sabat, I.; Neumann-Böhme, S.; Schreyögg, J.; Pita Barros, P.; Stargardt, T.; König, H.-H. Prevalence and determinants of probable depression and anxiety during the COVID-19 pandemic in seven countries: Longitudinal evidence from the European COVID Survey (ECOS). Psychiatry Res.. under review.

24. Ranta, M.; Silinskas, G.; Wilska, T.-A. Young adults' personal concerns during the COVID-19 pandemic in Finland: An issue for social concern. Int. J. Sociol. Soc. Policy 2020, 40, 1201-1219. [CrossRef] 
25. Finell, E.; Tiilikainen, M.; Jasinskaja-Lahti, I.; Hasan, N.; Muthana, F. Lived experience related to the COVID-19 pandemic among Arabic-, Russian-and Somali-speaking migrants in Finland. Int. J. Environ. Res. Public Health 2021, 18, 2601. [CrossRef]

26. Lund, C.; Brooke-Sumner, C.; Baingana, F.; Baron, E.C.; Breuer, E.; Chandra, P.; Haushofer, J.; Herrman, H.; Jordans, M.; Kieling, C. Social determinants of mental disorders and the Sustainable Development Goals: A systematic review of reviews. Lancet Psychiatry 2018, 5, 357-369. [CrossRef]

27. Fluharty, M.; Taylor, A.E.; Grabski, M.; Munafò, M.R. The association of cigarette smoking with depression and anxiety: A systematic review. Nicotine Tob. Res. 2016, 19, 3-13. [CrossRef]

28. Schwarzbach, M.; Luppa, M.; Forstmeier, S.; König, H.H.; Riedel-Heller, S.G. Social relations and depression in late life-A systematic review. Int. J. Geriatr. Psychiatry 2014, 29, 1-21. [CrossRef] [PubMed] 